\title{
Hepatosplenic T-Cell Lymphoma
}

\author{
Fahad I. Alsohaibani $\cdot$ Maheeba A. Abdulla • \\ Mousa M. Fagih
}

Received: 30 April 2010/Accepted: 10 December 2010/Published online: 12 February 2011

(C) Indian Society of Haematology \& Transfusion Medicine 2011

\begin{abstract}
We report an uncommon case of 38-year-old male patient with Hepatosplenic T-Cell lymphoma (HSTCL) which is a rare aggressive form of Peripheral T-Cell lymphoma that is characterized by primary extranodal disease with malignant T-cell proliferation in the liver, spleen, and bone marrow. Our patient presented with progressive painless jaundice, weight loss and massive hepatosplenomegaly. The diagnosis was challenging as he required an extensive investigations that ultimately showed the characteristic clinical, histopathologic, and cytogenetic features of hepatosplenic T-cell lymphoma.
\end{abstract}

Keywords Hepatosplenic - Lymphoma .

Hepatosplenomegaly

Hepatosplenic T-Cell Lymphoma (HSTCL) is an uncommon neoplasm that comprises $5 \%$ of peripheral T-cell lymphomas. The majority of cases express the $\gamma \delta$ T-cell receptor, however, recently, a small number of cases have been reported to express the $\alpha \beta$ T-cell receptor. Typical clinical features of this lymphoma include a predominance of young male patients, an aggressive clinical course, massive hepatosplenomegaly with sinusoidal infiltration of the liver, spleen, and bone marrow, minimal lymphadenopathy, expression or rearrangement of the $\gamma \delta$ T-cell

F. I. Alsohaibani $(\bowtie) \cdot$ M. A. Abdulla · M. M. Fagih Section of Gastroenterology, Department of Medicine (MBC-46), King Faisal Specialist Hospital \& Research Centre (KFSH\&RC), P. O. Box 3354, Riyadh 11211, Saudi Arabia e-mail: alsohaibani@hotmail.com

M. A. Abdulla

e-mail: maheeba@hotmail.com

M. M. Fagih

e-mail: mfage@yahoo.com; mfagih@kfshrc.edu.sa receptor, and frequent presence of an isochromosome $7 \mathrm{q}$ and trisomy 8 . This case highlights the importance of considering diagnosis of HSTCL in patients presenting with jaundice and massive hepatosplenomegaly.

\section{Case}

A 38-year-old Filipino male presented with a history of lethargy, painless jaundice, dark urine, weight loss (5 kg), and progressive abdominal distension over 3-month-period. He denied history of blood transfusion, significant alcohol consumption and high risk behaviors. He had no history of drug ingestion including acetaminophen and use of herbal remedies. On physical examination; he looked well but deeply jaundiced. His vital signs were stable. There were no lymphadenopathy or peripheral stigmata of chronic liver disease. His abdomen was distended with massive hepatosplenomegaly but without clinically detectable ascites.

His initial blood work showed: hemoglobin of $122 \mathrm{~g} / \mathrm{l}$, WBCs count of $3.8 \times 10^{9} / 1$ (73\% neutrophils, $16 \%$ lymphocytes, $3 \%$ monocytes, $1 \%$ eosinophils), platelets of $114 \times 10^{9} / 1$ and his peripheral blood film showed mild pancytopenia with mild atypical reactive lymphocytes. The rest of investigations were as follows: albumin $39 \mathrm{~g} / \mathrm{l}$, bilirubin (total $63 \mu \mathrm{mol} / \mathrm{l}$, direct $48 \mu \mathrm{mol} / \mathrm{l}$ ), ALT $355 \mathrm{IU} / \mathrm{l}$, alkaline phosphatase $719 \mathrm{IU} / \mathrm{l}$, creatinine $65 \mu \mathrm{mol} / \mathrm{l}$, prothrombin time $13.5 \mathrm{~s}$. Serology for common hepatotropic viruses including HAV IgG, HBsAg, anti-HCV and quantitative EBV were negative. Screening tests for human immunodeficiency virus, malaria, schistosomiasis, leishmaniasis, tuberculosis, and common metabolic and autoimmune disorders were also negative. CT scan of the abdomen showed massive hepatosplenomegaly with minimal ascites and scattered small mesenteric lymph nodes. 
As a differential diagnosis, we considered hematological malignancies including leukemia, lymphoma and myeloproliferative disorders and infiltrative disorders such as amyloidosis and sarcoidosis. The latter was ruled out with normal $24 \mathrm{~h}$ urinary calcium level and angiotensin converting enzyme level. The patient underwent bone marrow aspirate and biopsy which showed cellular marrow with increased megakaryopoiesis, active erythropoiesis and granulopoiesis without evidence of involvement by leukemia, lymphoma or any other infiltrative disorders. Liver biopsy showed moderate portal infiltration by small size lymphocytes and mild portal fibrosis. The bile ducts were present in normal numbers but with periductal infiltrate. Few small non-caseating granulomata were seen within hepatic lobules. There were no cholestasis or Mallory bodies detected (Fig. 1). Despite these extensive investigations, the diagnosis was not very clear and unfortunately the patient's general condition started to deteriorate with increase of his ascites and worsening pancytopenia and hepatic function. At that stage, his investigations were as follows: hemoglobin $107 \mathrm{~g} / \mathrm{l}$, WBCs $1.94 \times 10^{9} / 1$, platelet $77 \times 10^{9} / \mathrm{l}$, albumin $24 \mathrm{~g} / \mathrm{l}$, total bilirubin $170 \mathrm{mmol} / \mathrm{l}$, ALT $88 \mathrm{IU} / 1$, alkaline phosphatase $625 \mathrm{IU} / \mathrm{l}$. Septic workup was negative. Because the diagnosis was not definite at that point, and the patient became more pancytopenic, we elected to proceed with splenectomy for a diagnostic and therapeutic purpose. The procedure was uneventful and resulted in dramatic improvement in his cytopenia. The spleen was congested, measuring $31 \times 20 \times 5 \mathrm{~cm}$ and weighting $2423 \mathrm{~g}$. Slicing of the spleen reveals a homogenous brown-red parenchyma with focal golden-yellow area measuring $2 \mathrm{~cm}$ in maximum

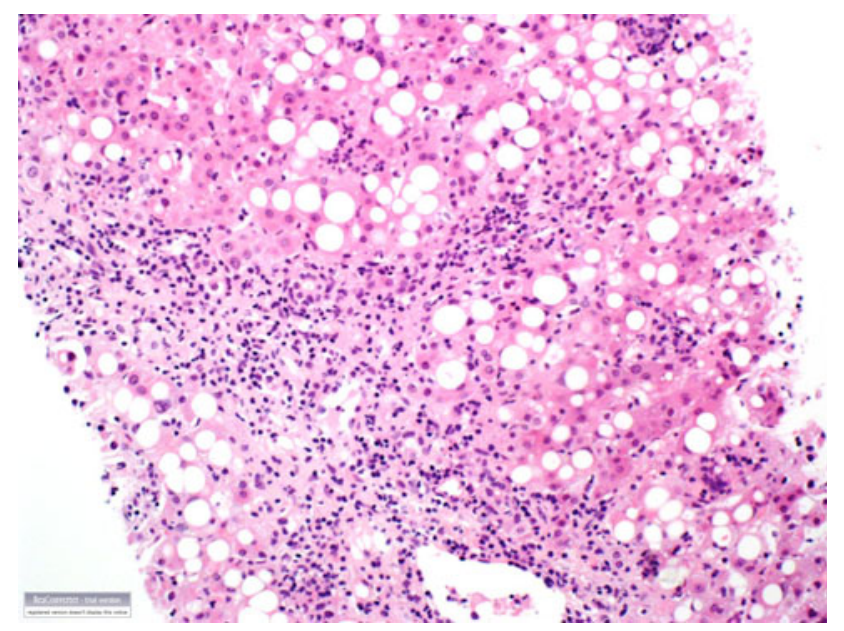

Fig. 1 Liver biopsy showing small lymphocytes infiltrating the portal tract as well as the adjacent liver lobule. Histologically the lymphocytes are morphologically similar to that seen within the splenic red pulp. Few small non-necrotizing granulomata are seen as well

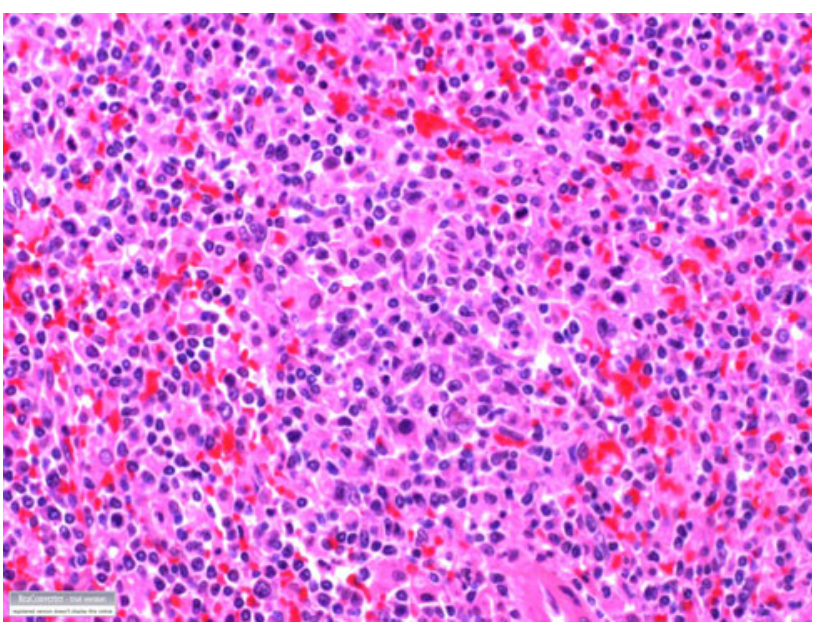

Fig. 2 High power view of the splenic pulp infiltrated by atypical small lymphocytes with hyperchromatic nuclei and few mitoses are seen

diameter. On microscopic examination, the red pulp and most of the white pulp were replaced by atypical small sized lymphoid cells with hyperchromatic nuclei, of which some showed atypical mitoses (Fig. 2). Immunohistochemical stains were performed and showed positive staining for CD3, CD7, CD56 and Granzyme B (Fig. 3, 4). They lacked the expression for CD4, CD5, CD8, CD20, CD30 and CD79a.

Retrospectively, immunohistochemistry stain was performed on the liver and bone marrow biopsies showed the same immunohistochemical profile as of that of the spleen (Fig. 5). This indicated involvement of spleen, liver and bone marrow by T-cell lymphoma. Flow-cytometry from ultrasonographic guided ascitic fluid aspiration revealed polyclonal $\mathrm{T}$ lymphocytes with intact expression of all $\mathrm{T}$ cells-associated antigens and CD4:CD8 ratio of one to one.

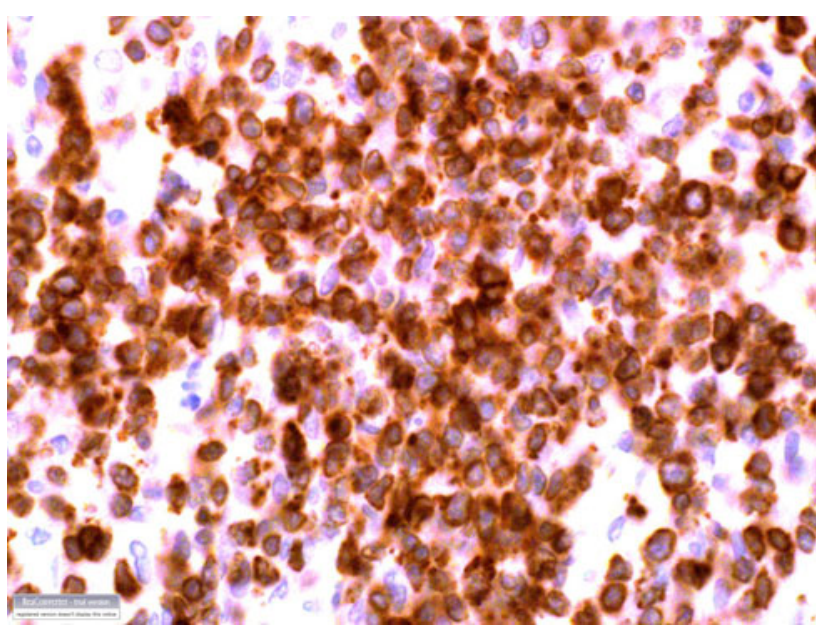

Fig. 3 CD3 immunohistochemical staining. Most of the cells are positive (spleen) 


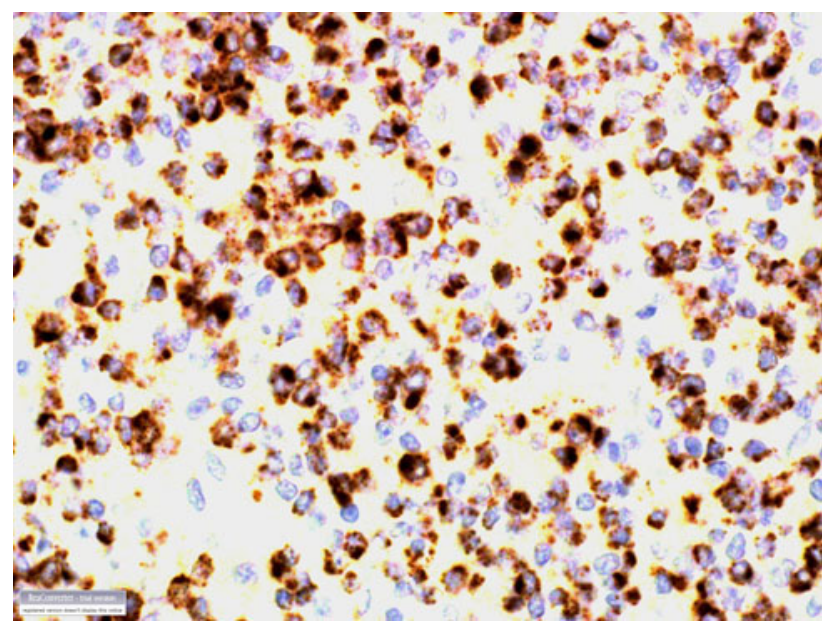

Fig. 4 The atypical lymphocytes are positive for Granzyme B (spleen)

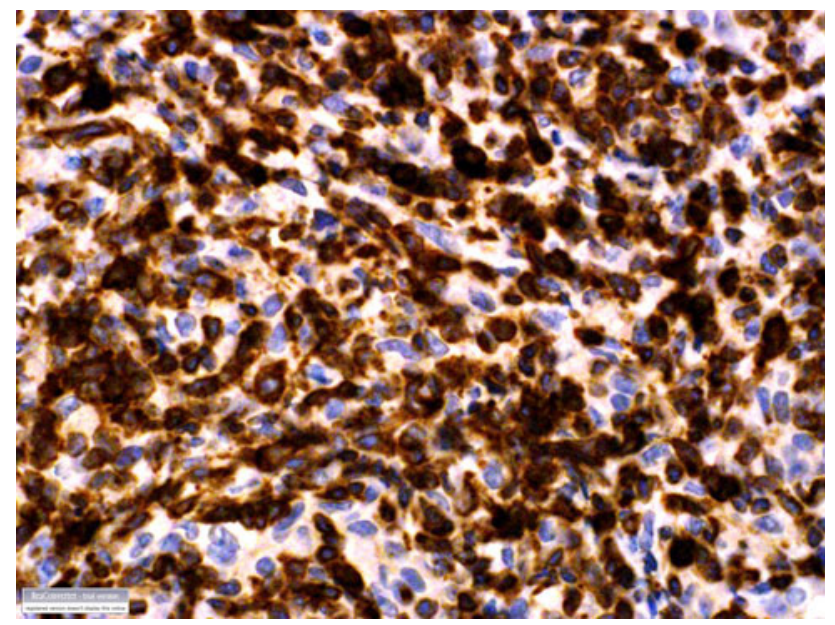

Fig. 5 The atypical lymphocytic infiltrates are positive for CD3 (liver)

Approximately $20 \%$ of the cells were positive for CD2, CD7 and CD56 but negative for CD3 and CD5 and those are considered as natural killer (NK) cells. Cytogenetic studies by FISH were conducted on bone marrow aspirate that showed complex cytogenetic abnormalities including trisomy 8 and trisomy 5. Combination of the clinical features, histological findings, flow-cytometry and genetic study of the bone marrow, the final diagnosis was hepatosplenic T-cell lymphoma.

After consultation with the Oncology Service and explaining the disease to the patient with its prognosis, it was decided to give him a trial of adjustable doses of methylprednisolone and cyclophosphamide. He received a total of two cycles of chemotherapy but unfortunately without significant clinical, hematological or biochemical responses and he passed away 3 weeks later.

\section{Discussion}

Hepatosplenic T-cell lymphoma is a rare entity of peripheral T-cell lymphomas that is characterized by hepatosplenomegaly without significant peripheral lymphadenopathy. $[1,2]$ Initially, the term 'gamma-delta hepatosplenic T-cell lymphoma was proposed as a provisional entity in the Revised European-American Lymphoma (REAL) classification. However, identification of patients who demonstrated an alpha-beta phenotype with the clinicopathologic features of HSTCL, the term 'hepatosplenic T-cell lymphoma' was adopted for use in the current World Health Organization classification [3-8].

The incidence of HSTCL is unknown. However, since its initial description in 1990 by Farcet et al. more than 150 cases have been reported in the literature, $[9,10]$ approximately $20 \%$ of these cases occurred in young men with history of immunosuppression including solid organ transplantation and leukemia. In addition, patients with inflammatory bowel diseases receiving immunosuppressant and anti-tumor necrosis factor- $\alpha$ agent are also at risk for developing HSTCL. Clinically, patients with HSTCL present with B-symptoms, jaundice and hepatosplenomegaly. Lymphadenopathy has been reported only in a few patients during the course of the disease. The predominant laboratory findings include pancytopenia and deranged liver chemistry. The diagnosis of HSTCL is not always straightforward because of the rarity of the disease and occasionally the misleading symptoms. Therefore, in most cases patients will require liver biopsy and/or splenectomy to establish the diagnosis.

Histologically, small to intermediate-size $\mathrm{T}$ lymphocytes preferentially infiltrate the sinusoids of liver and splenic red pulp [11]. Bone marrow is involved in approximately two-thirds of patients at diagnosis [12]. The lymphoma cells are typically $\mathrm{CD} 2^{+}, \mathrm{CD}^{+}, \mathrm{CD}^{-}, \mathrm{CD}^{-}$, $\mathrm{CD} 7^{+}, \mathrm{CD} 8^{-} \mathrm{CD} 42^{+}, \mathrm{CD} 52^{+}, \mathrm{CD} 76^{+}, \mathrm{CD} 82^{+}$with either gamma-delta or alpha-beta T-cell phenotypic receptor expression. Karyotypic studies frequently showed an isochromosome 7q, which may be accompanied by trisomy 8 and loss of a sex chromosome [2,11, 13-16]. Unfortunately, this aggressive type of lymphoma lacks any standardized treatment and the overall prognosis considered to be poor with survival duration varies widely from 0 to 5 years. [12] Treatment with standard anthracycline-containing chemotherapy regimens has been disappointing, with variable response rates and a short median survival of 8 months (ranging from 0 to 72 months). The largest published experience (15 patients) was reported by a group from M.D. Anderson Cancer Center with a complete response achieved in 7 of 14 patients who received chemotherapy and a median overall survival was 11 months (range 2-36 + months). [3] Risk factors associated with 
worse outcome included male gender, failure to achieve a $\mathrm{CR}$, history of immunocompromise, absence of a T-cell receptor gene rearrangement in the gamma chain and liver involvement at presentation [1, 3, 17].

Our case confirmed that hepatosplenic T-cell lymphoma develops most often in young men and usually manifested as hepatosplenomegaly without peripheral lymphadenopathy. Unfortunately, the prognosis is poor; however, more insight in the biology of malignant T-cells as well as description of more cases with new clinical and biologic features may hopefully contribute to develop new therapeutic options in the future.

\section{References}

1. Macon WR, Levy NB, Kurtin PJ, Salhany KE, Elkhalifa MY, Casey TT et al (2001) Hepatosplenic alphabeta T-cell lymphomas: a report of 14 cases and comparison with hepatosplenic gammadelta T-cell lymphomas. Am J Surg Pathol 25(3):285-296

2. Cooke CB, Krenacs L, Stetler-Stevenson M, Greiner TC, Raffeld M, Kingma DW et al (1996) Hepatosplenic T-cell lymphoma: a distinct clinicopathologic entity of cytotoxic gamma delta T-cell origin. Blood 88(11):4265-4274

3. Falchook GS, Vega F, Dang NH, Samaniego F, Rodriguez MA, Champlin RE et al (2009) Hepatosplenic gamma-delta T-cell lymphoma: clinicopathological features and treatment. Ann Oncol 20(6):1080-1085

4. Harris NL, Jaffe ES, Diebold J, Flandrin G, Muller-Hermelink HK, Vardiman J et al (1999) The World Health Organization classification of neoplastic diseases of the hematopoietic and lymphoid tissues. Report of the Clinical Advisory Committee meeting, Airlie House, Virginia, November, 1997. Ann Oncol 10(12):1419-1432

5. Harris NL, Jaffe ES, Stein H, Banks PM, Chan JK, Cleary ML et al (1994) A revised European-American classification of lymphoid neoplasms: a proposal from the international lymphoma study group. Blood 84(5):1361-1392

6. Lai R, Larratt LM, Etches W, Mortimer ST, Jewell LD, Dabbagh L et al (2000) Hepatosplenic T-cell lymphoma of alpha beta lineage in a 16-year-old boy presenting with hemolytic anemia and thrombocytopenia. Am J Surg Pathol 24(3):459-463
7. Suarez F, Wlodarska I, Rigal-Huguet F, Mempel M, MartinGarcia N, Farcet JP et al (2000) Hepatosplenic alphabeta T-cell lymphoma: an unusual case with clinical, histologic, and cytogenetic features of gammadelta hepatosplenic T-cell lymphoma. Am J Surg Pathol 24(7):1027-1032

8. The Non-Hodgkin's Lymphoma Classification Project (1997) A clinical evaluation of the International Lymphoma Study Group classification of non-Hodgkin's lymphoma. Blood 89(11): 3909-3918

9. Farcet JP, Gaulard P, Marolleau JP, Le Couedic JP, Henni T, Gourdin MF et al (1990) Hepatosplenic T-cell lymphoma: sinu$\mathrm{sal} /$ sinusoidal localization of malignant cells expressing the Tcell receptor gamma delta. Blood 75(11):2213-2219

10. Beigel F, Jurgens M, Tillack C, Subklewe M, Mayr D, Goke B et al (2009) Hepatosplenic T-cell lymphoma in a patient with Crohn's disease. Nat Rev Gastroenterol Hepatol 6(7):433-436

11. Salhany KE, Feldman M, Kahn MJ, Peritt D, Schretzenmair RD, Wilson DM et al (1997) Hepatosplenic gammadelta T-cell lymphoma: ultrastructural, immunophenotypic, and functional evidence for cytotoxic T lymphocyte differentiation. Hum Pathol 28(6):674-685

12. Weidmann E (2000) Hepatosplenic T cell lymphoma. A review on 45 cases since the first report describing the disease as a distinct lymphoma entity in 1990. Leukemia 14(6):991-997

13. Kraus MD, Crawford DF, Kaleem Z, Shenoy S, MacArthur CA, Longtine JA (1998) T gamma/delta hepatosplenic lymphoma in a heart transplant patient after an Epstein-Barr virus positive lymphoproliferative disorder: a case report. Cancer 82(5):983-992

14. Wang CC, Tien HF, Lin MT, Su IJ, Wang CH, Chuang SM et al (1995) Consistent presence of isochromosome 7q in hepatosplenic $\mathrm{T}$ gamma/delta lymphoma: a new cytogenetic-clinicopathologic entity. Genes Chromosomes Cancer 12(3):161-164

15. Francois A, Lesesve JF, Stamatoullas A, Comoz F, Lenormand B, Etienne I et al (1997) Hepatosplenic gamma/delta T-cell lymphoma: a report of two cases in immunocompromised patients, associated with isochromosome 7q. Am J Surg Pathol 21(7): 781-790

16. Jonveaux P, Daniel MT, Martel V, Maarek O, Berger R (1996) Isochromosome $7 \mathrm{q}$ and trisomy 8 are consistent primary, nonrandom chromosomal abnormalities associated with hepatosplenic T gamma/delta lymphoma. Leukemia 10(9):1453-1455

17. Belhadj K, Reyes F, Farcet JP, Tilly H, Bastard C, Angonin R et al (2003) Hepatosplenic gammadelta T-cell lymphoma is a rare clinicopathologic entity with poor outcome: report on a series of 21 patients. Blood 102(13):4261-4269 